Rec . Nov. 2000

\title{
Has primary overlap replaced end-to-end repair for anal sphincter rupture during vaginal delivery?
}

\section{Nagwa Abd El-Ghaffar Mohamed, *Maha Abd El-Mongi Abd El-Rahman}

\author{
Department of Obstetrics and Gynaecology, *Department of General Surgery \\ Faculty of Medicine for Girls Al-Azhar University, Cairo, Egypt.
}

\begin{abstract}
:
Twenty primigravidae women were included in this study. Their age ranged from (20-32) years. They were requiring primary repair for third degree tear occurring during vaginal delivery. All repairs were performed immediately after obstetric disruption. A ruptured internal sphincter was repaired separately and the torn ends of the external sphincter were overlaped in 10 women and approximated as end-to-end in the other 10 women, and sutured with $3 / 0$ polydioxanone sulphate sutures. Sixteen women were followed up, and for all bowel function, clinical assessement, and anal endosonography were performed at a mean of 120 days after delivary. Eleven percent had persistent sonographic external sphincter defects with overlap, and $57 \%$ with end to end repair. Also, we found similar percent of internal sphincter defects with overlap, and end-toend repair. There was no significant difference between the two techniques with regard to the clinical outcome. Based on the preceding results it would appear that sonographic image for external sphincter is better with overlap than end-to-end repair, but we can not conclusively prove that overlap is superior to the end-to-end repair for better clinical outcome obtained from both techniques.
\end{abstract}

\section{Introduction:}

Vaginal delivery is the major cause of anal incontinence in women ${ }^{(14)}$. Anal endosonography revealed occult sphincter injury after vaginal delivery even in the absence of sphincter tears diagnosed at birth ${ }^{(11)}$. Sphincter rupture is classified as a third degree tear when the fibers of the anal sphincter are torn, and fourth degree if in addition the anal mucosa is breached ${ }^{(2)}$. The incidence of anal sphincter rupture varies between $0.5 \%$ and $2.5 \%$ in centres where mediolateral episiotomy is practised, compared with $7 \%$ in units performing a midline episiotomy ${ }^{(16)}$. Modification in obstetric practice, including reduced ocular surveillance of perineum, lack of manual perineal protection, complicated birth positions, deficient support and assistance at delivery, are associated with an increased risk of sphincter lacerations. Nulliparity, instrumental delivery, high birth weight, shoulder dystocia, fetal presentation, episiotomy and epidural anaesthesia are also considered risk factors ${ }^{(9)}$. Primary anal sphincter repair is generally performed by an obstetrician immediately after delivery using the technique of end-toend approximation of the torn sphincter 


\section{Has primary overlap replaced}

muscle with interrupted or "figure of 8 " sutures. By contrast, surgeons perform -ing secondary anal sphincter repair for anal incontinence favour the overlap technique of repair, as long term follow up indicates restoration of continence in $76 \%$ of patients ${ }^{(3)}$. The aim of this study is to compare the outcome of primary repair using the overlap versus end-to-end repair.

\section{Patients and Methods:}

This work was performed over 2.5 year period started from January 1998. The study included 20 primigrav -idae women with age ranged form (2032) years. They needed primary repair for third degree tear occurring during vaginal delivery. Ten women randomi sed to primary overlap and 10 to end-toend repair.

The following procedures were performed by an obstetrician and a surgeon at Al-Zahraa University Hosp ital. All repairs were performed imme diately after obstetric disruption in the operating theatre under general anaesthesia. This is an important prerequisite, particularly for overlap repair, as the inherent tone in the sphincter muscle can cause the torn muscle ends to retract within its sheath. Muscle relaxation is necessary to retrieve the ends and overlap without tension.

We prepared a special "perineal repair pack" which included specific instruments such as four Allis forceps, McIndoe scissors and Spencer Wells forceps. The woman was placed in the lithotomy position and the repair was performed under full aseptic conditions. The sphincter muscles were repaired with $3 / 0$ polydioxanone sulphate sutur es. We chose a long lasting absorbable suture as we found that non absorbable sutures can cause stitch abscesses and the sharp ends of the suture can cause discomfort, necessitating removal. When a tear of the internal anal sphinc ter was recognised we repaired it separ ately. The internal anal sphincter lies between the external sphincter and the anal epithelium. It is paler than the striated external sphincter and the muscle fibres run in a circular fashion. The ends of the torn muscle were grasped with Allis forceps and an endto-end repair was performed with interrupted $3 / 0$ polydioxanone sulphate sutures. The torn ends of the external sphincter were identified and grasped with Allis tissue forceps. The muscle was then mobilised and pulled across to overlap in a "double-breasted" fashion. The torn ends of the external sphincter were then overlapped using polydioxa none sulphate $3 / 0$ sutures. This techn ique was performed for 10 women, while end-to-end approximation by "figure of 8 " sutures was performed to the other 10 women. The muscles of the perineal body were reconstructed with $2 / 0$ vicryl sutures to provide support to the sphincter repair. Vaginal epithelium was repaired with contin uous $3 / 0$ vicryl sutures. Lastly the perineal skin was approximated with a $3 / 0$ vicryl subcuticular suture. Intrave nous antibiotics (Cefuroxime $1.5 \mathrm{~g}$ and Metronidazole $500 \mathrm{mg}$ ) were comm enced intraoperatively and continued orally for one week, to avoid infection which might jeopardise repair and lead to incontinence or fistula formation. All women were given stool softeners and a bulking agent as straining to pass a bolus of hard stool may disrupt the repair.

Pre-delivery bowel and bladder symptoms were assessed. None of the women had a previous history of bowel disorder or anorectal surgery. The day after repair was assessed by using a standardised symptom questionnaire. At the three month follow up visit the 
questionnaire was completed again. Patients were asked to rate their postop -erative improvement as a percentage. Clinical examination was performed by an obstetrician and a surgeon and clinical parameters were recorded; anterior anal sphincter length to assess changes in its length after operation, the presence or absence of a cutaneous anal reflex, a palpable gap in the sphincter, and the anorectal angle; resting anal pressure, voluntary squeeze pressure and cough reflex were assessed clinically on a scale of 0 (normal) to 3 (grossly abnormal) without the aid of electrophysiological measurements. Ea -ch woman was designated as having a "normal" or "abnormal" sphincter mech -anism based on an overall assessment of the recorded clinical parameters.

Anal endosonography was perfo rmed using kret's combison 311 (Austria) with $7.5 \mathrm{MHz}$ transducer bipla -ner. A plastic con filled with degassed water, covered the transducer head to allow withdrawal into the anal canal. The probe was covered by a lubricated condom and examinations were perfo rmed in left lateral position. Anal canal structures were measured at three levels: high at the puborectalis/deep external sphincter level, mid at the external sphincter where the internal sphincter was of maximal thickness, and low at the subcutaneous external sphin -cter just caudal to the termination of the internal sphincter. The postoperative aspect of the external sphincter was scored as improved when at any level of the external sphincter signs of overlap or complete apposition of muscle were seen; if these were not present the aspect of the external sphincter was scored as not improved.

\section{Results:}

Sixteen women were followed up (9 with overlap and 7 with end-to-end repair) at a mean of 120 days range (40220). Four asymptomatic women declined investigations at follow up. The median time between delivery and repair was 55 minutes, range (0-460). The long delay in one patient (460 minutes) was due to priority being given to another obstetric emergency. The median operative duration was 60 min -utes, range (30-100) but this included repair of additional vaginal tears and teaching.

A torn internal sphincter was identified clinically and repaired in 12 (75\%) of the 16 women. Follow up with anal endosonography revealed 2 (50\%) internal sphincter defects in the remaining 4 women in whom a torn internal sphincter was not identified.

Overlap of the external sphincter was demonstrated sonographically in 6 (67\%) women. Of the remaining three in whom overlap was not demonstrated, defect was identified in one. However persistent external anal sphincter defects were found in 4 (57\%) women with end-to-end repair.

None of the women had persistent perianal pain or difficulty with bowel evacuation at follow up. None devel oped an anorectal vaginal fistula. Fourt -een of the 16 women had resumed sexual activity at the time of follow up. Two women (with overlap repair) com plained of new superficial dyspareunia.

Table (1) shows the characteristics of women. Table (2) shows bowel sympto -ms and endosonography findings. Figures (1), (2) and (3) show diagrammatic illustration for both type of repair. Figures (4) and (5) show endosonog raphic image for both type of repair. 


\section{Has primary overlap replaced}

Table (1): Characteristics of women. Values are given as number (n), $(n=20)$ or mean (range) or mean (SD)

\begin{tabular}{|l|l|}
\hline Age & $24(20-32)$ \\
Primiparous & 20 \\
Episiotomy & \\
$\quad *$ Mediolateral & 17 \\
$\quad *$ Median & 3 \\
Instrumental delivery & 5 \\
Birth weight $(\mathrm{kg})$ & $3.68(0.37)$ \\
\hline
\end{tabular}

Table (2): $\quad$ Bowel symptoms and endosonography findings in women who had undergone (overlap and end-to-end repair).

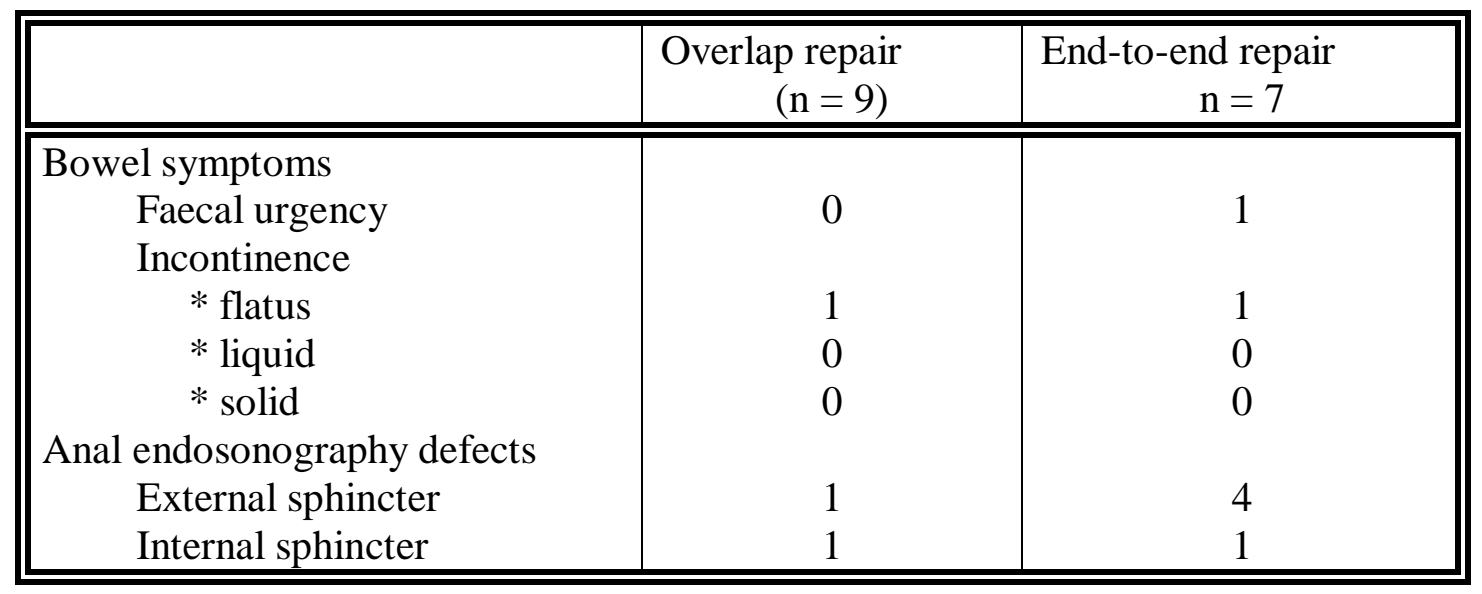

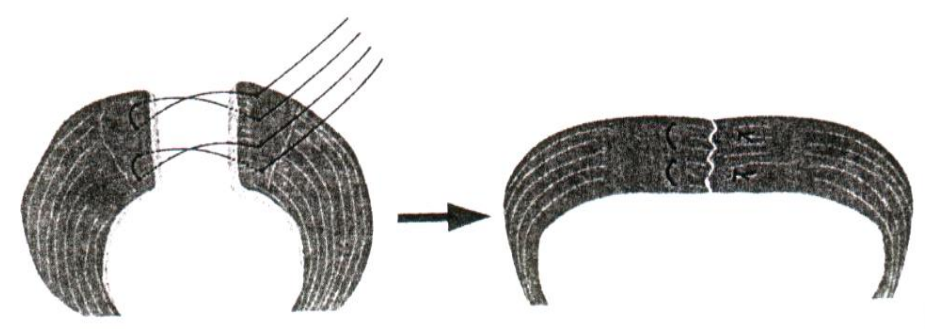

Fig. (1): Shows diagram to illustrate the technique of end-to-end repair of the external sphincter with 2 "figure of 8 " sutures. 


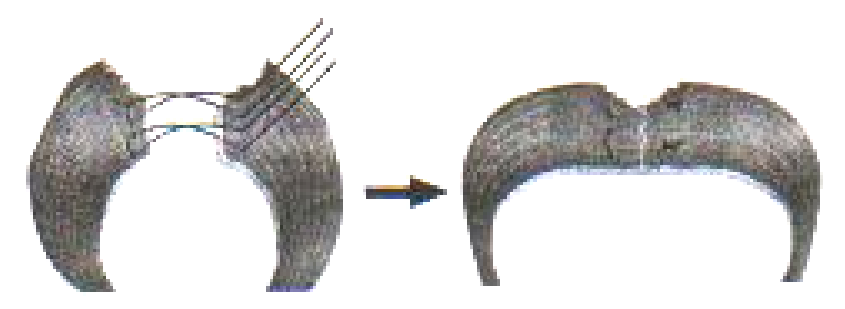

Fig. (2): Shows diagram to illustrate incomplete apposition as a possible cause for poor outcome following end-to-end repair.

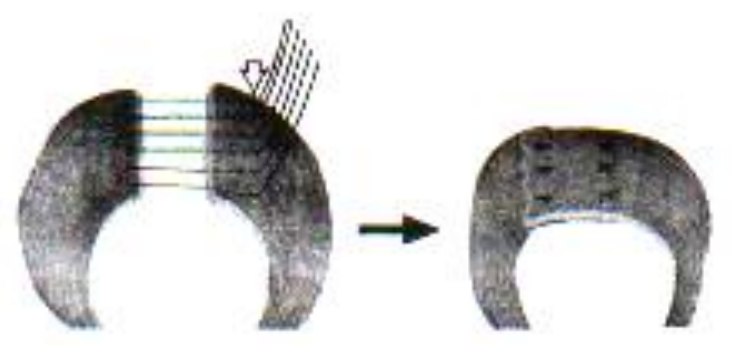

Fig. (3): $\quad$ shows diagram to illustrate the technique of overlap repair of the external sphincter.

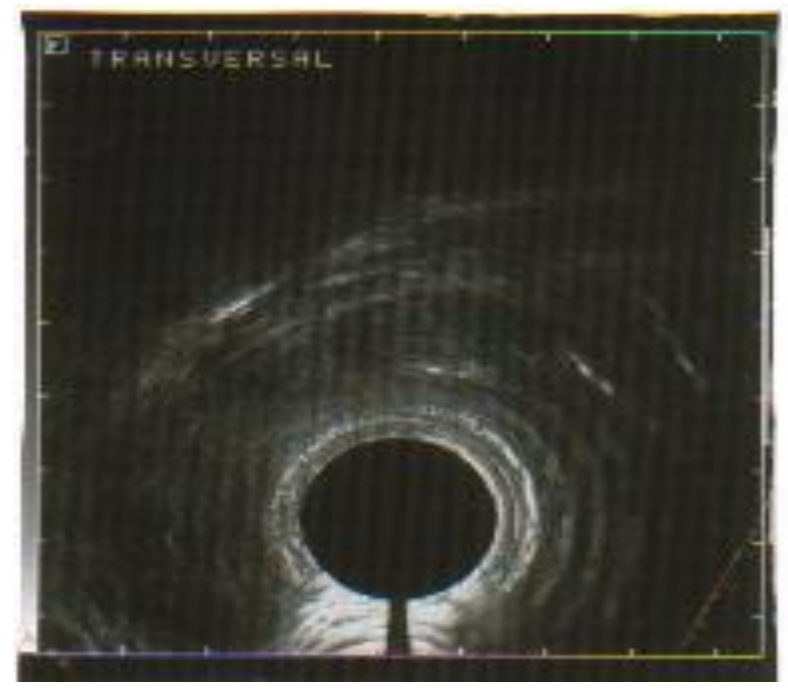

Fig. (4): Shows anal endosonographic image demonstrating overlap of the two ends of the external sphincter. 


\section{Has primary overlap replaced}

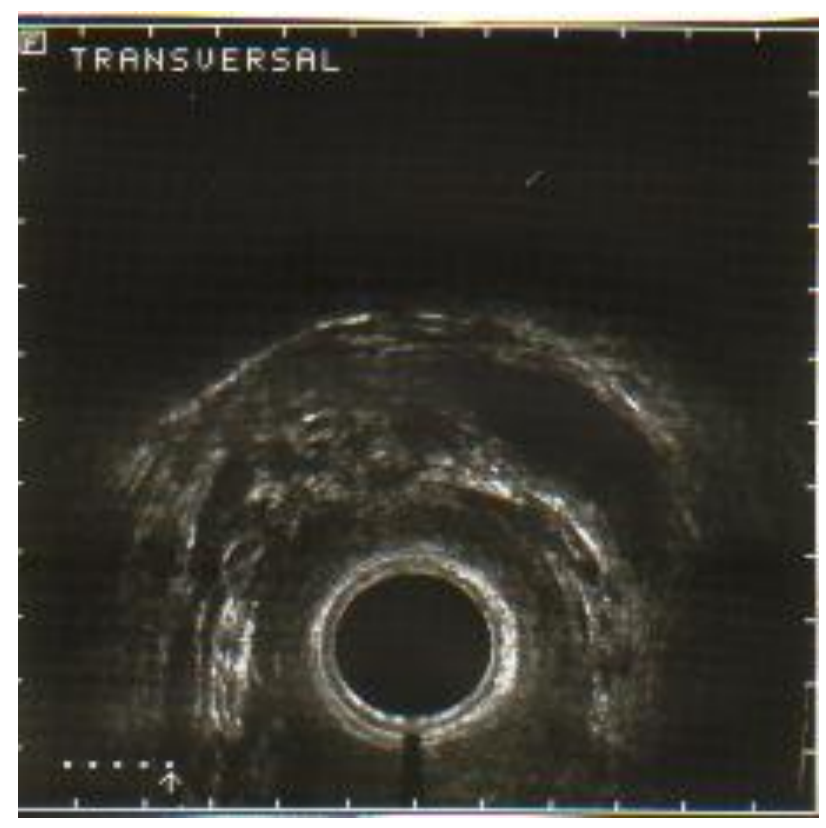

Fig. (5): Shows anal endosonographic image demonstrating an external sphincter defect following an end-to-end repair.

\section{Discussion:}

This study describes primary repair of the third degree tear using either (overlap or end-to-end approxim ation) of the external sphincter. We performed primary repair immediately after obstetric disruption to obtain better clinical outcome. In contrast to this Haadem et al., (1990) assumed that anorectal presure profiles in women who sustain a third degree tear improved during the first 3 months postpartum but show no subsequent improvement thereafter, so 3 months seem an appropriate arbitrary interval after delivery to assess women who have sustained a third-degree tear. In this work better clinical improvement obtained with immediate primary repair this may be related to the rigid protocol used. Our results coincided with Sultan et al., (1999) and Alcalay et al., (1995), who found that the immediate and first operation produces the best chance of sustained success. Walsh et al., (1996) believed that obstetric trauma causes significant anorectal dysfunction and colorectal follow up should be manda tory for all women who sustain a third degree tear during labour regardless of who performs the primary repair a surgeon or an obstetrician.

In this study we chose not to perform tests of pudendal nerve function. This is in agreement with Sultan et al., (1995) who found that abnormal pudendal nerve motor latency bears no relationship to the clinical outcome of primary repair. Also Sultan et al., (1997) found that all women with impa -ired continence following primary rep -air had sonographic defects in both internal and external sphincters while pundendal nerve motor latencies were normal in the majority of 
patients. However Laurberg et al., (1988) found that poor outcome of secondary sphin -cter repair is related to a pudendal neuropathy as measured by a prolonged pudendal nerve motor Latency. Ternent et al., (1997) failed to support this theory.

Sultan et al., (1995) has been sceptical of overlap technique as a primary procedure, and critics argued that overlapping freshly torn and friable muscle will not be technically possible, as suture material would cut through muscle under tension. However in this work the overlap repair requires clear visualisa-tion of the ends of the external sphincter in its entirety and overlapping allows for a greater surface area of contact between muscle. If further retraction of the overlapped muscle ends were to occur, it is highly probably that muscle continuity would be maintained. In the present study overlap repair associated with a significantly better clinical outcome as only one woman admitted anal inconti nence, she was incontinent to flatus only. Also we found that the presence of overlapping muscle sonographically correlated with a good clinical outcome in most patients but not all. This highlights the need for other measures of sphincter function, such as manometry. Other factors such as sensory function and colonic motility, may contribute to the maintenance of continence. In contrast Engel et al., (1994) performed endosono -graphy and neurophysiological tests before and after overlap anterior anal sphincter repair in women with anal incontinence.

A good clinical outcome was reported in most patients and failure of repair was related to persiste -nce or recurrence of an external sphi -ncter defects as demonstrated by anal endosonography.
In 1955, Fulsher and Fearl claimed excellent results using a technique in which only the outer fascial layer of the external sphincter was approximated and no sutures were placed through muscle. However these results have not been reproduced. Currently the most common type of repair performed by obstetricians is an end-to-end approximation of the external anal sphincter either by interrupted or by "figure of 8 " sutures. It can result in ischaemia of the muscle ends. Furthermore, failure to identify the full width of the external sphincter would result in approximation of only part of the muscle. This may also explain the shorter anal length. In this study we found better clinical improvement inspite of the presence of persistent external anal sphincter defects in some patients. Our results agree with the hypothesis of Nielsen et al., (1992) who attribute the continence of this group of women with external sphincter defect to their youth and inherent ability to compensate for the external sphincter defect. Some of these women may well become incontinent as they get older, particularly if they have further vaginal deliveries. However, Haadem et al., (1990) found that poor clinical outcome appear to be related to reduced external sphincter strength and short anal length.

In this work we did not attempt overlap of the internal sphincter, as this would require further dissection and mobilis ation. Furthermore, the structural desi gn of smooth muscle, which has less fibrous tissue than striated muscle, makes it more likely to tear when sutures are placed under tension. The majority of women restored internal sphincter integrity if the torn ends of the muscle are approximated during Prim ary repair. However, Meyenberger et 
al., (1996) performed secondary overlap repair of internal sphincter in women suffering from anal incontinence with an isolated sonographic internal anal sphincter defect. Most women reported excellent results. Our results showed internal sphincter defects identified sonographically in those women in whom a tear of the internal sphincter was not recognised at repair this is in keeping with Sultan et al., (1998) who observed occult defects following normal vaginal delivery and instrum ental delivery.

\section{Conclusion:}

Based on the preceding results it would appear that this study has demonstrated that sonographical image for external sphincter is better with overlap repair than end-to-end approxi mation. Inspite of this we can not concl -usively prove that overlap repair is superior to the end-to-end repair for obtaining better clinical outcome.

\section{References:}

1. Alcalay M, Monga A, Stanton SL. Burch colposuspension: a 10-20 year follow up. $\mathrm{Br} \mathrm{J}$ Obstet Gynaecol 1995; 102: 740-745.

2. Cunningham FG, MacDonald PC, Gant NF, Leveno KJ, Gilstrap LC III. Williams Obstetrics - Newark: Prentice Hall, 1993: 388-393.

3. Engel AF, Kamm MA, Sultan AH, Bartram CI, Nicholls RJ. Anterior anal sphincter repair in patients with obstetric trauma. $\mathrm{Br}$ J Surg 1994; 81: 1231-1234.

4. Fulsher RW, Fearl CL. The third degree laceration in modern obstetrics. Am J obstet Gynecol 1955; 69: 786-793.
5. Haadem K, Dahlstrom JA, Lingman G. Anal sphincter function after delivery: a prospective study in women with sphincter rupture and controls. Eur J Obstet Gynecol Reprod Med 1990; 35: 7-13.

6. Laurberg S, Swash $M$, Henry MM. Delayed external sphincter repair for obstetric tear. Br J Surg 1988; 75: 786-788.

7. Meyenberger C, Bertschinger P, Zala GF, Buchmann P. Anal sphincter defects in faecal incontinence: corre -lation between endosonography and surgery. Endoscopy 1996; 28: 217-224.

8. Nielsen MB, Hauge C, Rasmussen OO, Pedersen JF, Christiansen J. Anal endosono graphic findings in the follow up of primarily sutured sphincteric rupt ures. Br J Surg 1992; 79: 104-106.

9. Samuelsson E, Ladfors $\mathbf{L}$, Hagberg H. Anal sphincter tears prospective study of obstetric risk factors. Br J Obstet Gynaecol 2000; 107: 926-931.

10. Sultan AH, Kamm MA, Hudson CN. Obstetric perineal tears; an audit of training $\mathrm{J}$ Obstet Gynaecol 1995: 15:19-23.

11. Sultan АH. Anal incontinence after child birth. Curr Opinion Obstet Gynaecol 1997; 9: 320-324.

12. Sultan AH, Johanson RB, Carter JE. Occult anal sphincter trauma following randomized forceps and vacuum delivery. Int $\mathbf{J}$ Gynaecol Obstet 1998; 61: 113-119.

13. Sultan AH, Monga, AK, Kumar D, Stanton SL. Primary repair of obstetric and sphincter rupture using the overlap technique. Br J Obstet Gynecol 1999; 106: 318-323. 
14. Swash M. Faecal incon tinence. BMJ 1993; 307: 636-637.

15. Ternent CA, Shashidharan M, Blatchford GJ, Christensen MA, Thorson, AG, Sentovich SM. Transanal ultrasound and anorectal physiology findings affecting contin -ence after sphincteroplasty. Dis Colon Rectum 1997; 40: 462-467.

16. Tetzschner T, Sorensen M, Lose G, Christiansen J. Anal and urinary incontinence in women with obstetric anal sphincter rupture. $\mathrm{Br}$ J Obstet Gynaecol 1996; 103: 10341040.

17. Walsh CJ, Mooney EF, Upton GJ, Motson, RW. Incidence of third-degree perineal tears in labour and outcome after primary repair. $\mathrm{Br} \quad \mathrm{J}$ Surg 1996;83:218-221.

\section{هل عملية طى طرفى العضلة العاصرة الخارجية للشرج}

أفضل من عملية تقريب طرفى نفس العضلة الممزقة أثناء الولادة الطبيعية؟

$$
\text { نجوى عبد الغفار محمد - * مها عبد المنجى عبد الرحمن }
$$

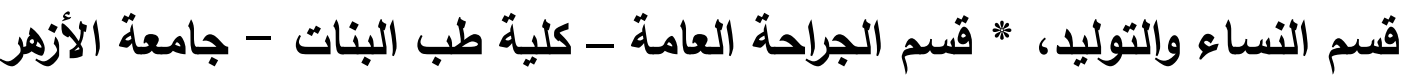
أجرى هذا البحث خـلال عامين ونصف بداية من يناير 1998 بمستشفى الزهراء الجامعى على عشرين سيدة لم

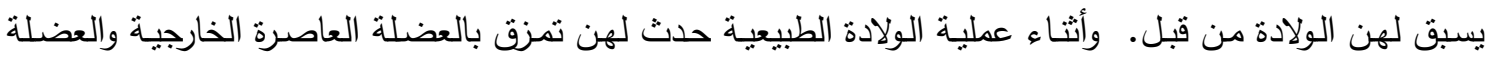

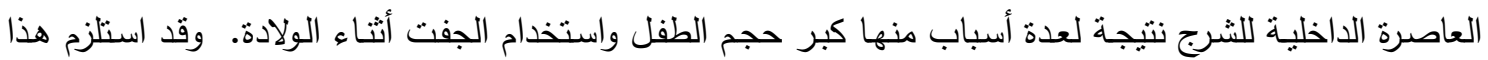
عملية إصلاح فورية بعد الولادة مباشرة. واستخدمنا طريقتين لإصلاح عضلة الثرج لمعرفة كفاءة وميزة كل طريقة عن الأخرى.

وقد قسمن السيدات عشوائياً إلى مجموعنين منساويتين:

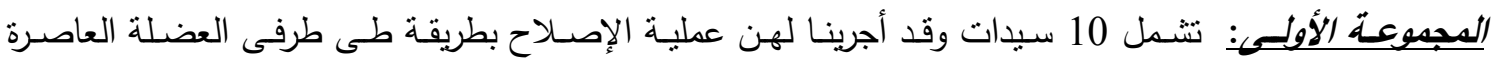

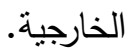

المجموعـة الثانيـة: تشمل 10 سيدات وقد أجرينا لهن عملية الإصـلاح بطريقة تقريب طرفى العضلة العاصـرة

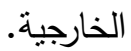

فى الوقت نفسه أجرينا لجميع السيدات عملية إصلاح للعضلة العاصرة الداخلية التى وجد بها تمزق بطريقة التقريب فقط. وبعد مضى حوالى ثلاثة شهور أجرينا متابعة للحالات فحضرت 16 سيدة فقط للمتابعة وامتتعت أربع سيدات عن الحضور لعدم وجود شكوى مرضية بعد العملية. وفى خلال المنابعة أجرينا فحوص إكلينيكية لجميع السيدات

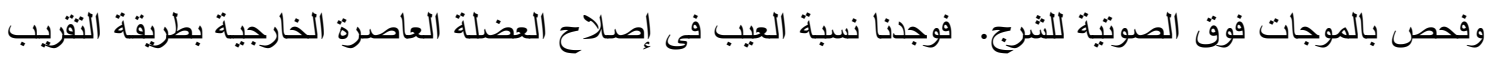
مرتفعة فى الوقت نفسه وجدناها منخفضة فى الإصلاح بالطى. أما نسبة العيب بالعضلة العاصرة الداخلية وجدناها

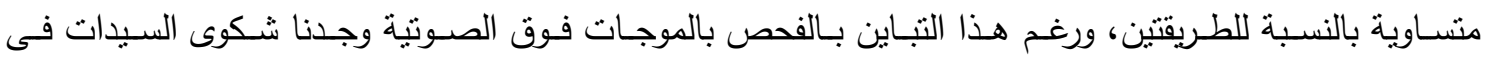

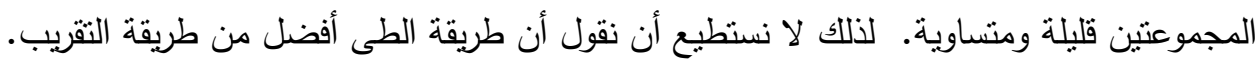

